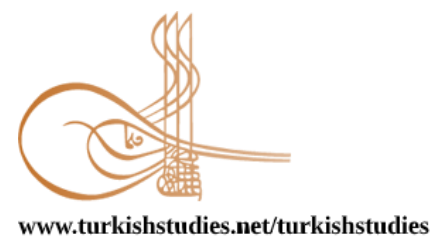

Turkish Studies

\title{
Geç Antik Dönem Kentlerinde Pagan Mekanların Dönüşümü ve Korunması Üzerine Görüşler
}

\author{
Transformation and Conservation of Pagan Spaces in Late Antique Cities
}

\author{
Şener Yıldırım*
}

\begin{abstract}
The most important factor in the establishment of the built environment of the cities in the Ancient Period was the financial support of the wealthy nobility who formed the city council. The quality of the structuring, which arose as a result of the nobility's desire to make the city they reside in beautiful and pleasant, must have definitely been directly proportional to the financial power of both the city and themselves. The financial challenges that began to emerge throughout the Roman Empire in Late Antiquity, as well as the resulting increased taxes, prompted wealthier citizens to spend less on urban public works. Financial and administrative power shifted from pagan urban nobility to Christian clergy and Christian philanthropists in Late Antiquity. The shift in power dynamics resulted in the rapid spread of Christian ecclesiastical structures in cities. It had not always been easy for religious structures to find a place in the urban built environment. As a solution for this issue, conversions in the form and function of pagan structures emerged. At this stage, it is observed that certain pagan structures were destroyed, while others were partially or totally converted. The magnitude and quality of this conversion emerge as being directly proportional to the city's financial power. It is seen that, in larger cities with better financial conditions, not only the preservation or the partial conversion of existing monumental structures, but also the maintenance, repair, and renovation of urban spaces, continues. The preservation of spaces associated with entirely discarded old religious beliefs implies the continuation of cultural memory as well as the existence of a preservative understanding. However, the fact that this preservative approach was more intensely pursued in relatively wealthy cities can be explained by the fact that the rise of this viewpoint was likewise tied to financial power.
\end{abstract}

Structured Abstract: All probable causes of the "transformation" in the urban dimension in Late Antiquity were considered in this study. However, mainly the financial factors were attempted to be revealed. The data referenced on this issue have been collected from monumental public buildings and urban spaces, which vary in density and quality from city to city, rather than the financial records of the period or archaeological finds directly tied to the economy. The cities in Anatolia's western and southern regions have been largely addressed in the study centered around a limited number of instances. The reason for this selection is the relative data redundancy caused by the concentration of archaeological studies in these regions.

The residents in a typical Roman city lived a social life in interaction with the city and the locations that the city had to offer. Agoras, theaters, colonnaded streets, baths, and other similar structures served as social and urban areas where urban residents interacted intensely in their daily lives. Temples, where

\footnotetext{
${ }^{*}$ Dr. Öğr. Üyesi, Mersin Üniversitesi Fen-Edebiyat Fakültesi, Sanat Tarihi Bölümü Asst. Prof. Dr., Mersin University Faculty of Science and Letters / Department of Art History ORCID 0000-0002- 9476-6431 seneryildirim@mersin.edu.tr
}

Cite as/ Atıf: Yıldırım, Ş. (2021). Geç antik dönem kentlerinde pagan mekanların dönüşümü ve korunması üzerine görüşler. Turkish Studies, 16(7), 379-394. https://dx.doi.org/10.7827/TurkishStudies.52863

Received/Geliş: 06 October/Ekim 2021

Accepted/Kabul: 27 December/Aralık 2021

Checked by plagiarism software

Published/Yayın: 31 December/Aralık 2021

\section{BY-NC 4.0}


ordinary people were prohibited to use the interior space, can also be considered urban spaces due to their extravagant frontal architectures.

For the people of the Ancient Period, who were proud of the city they resided in, the beauty and magnificence of their cities became the subject of competition with other cities, and this circumstance was one of the causes that directly affected the appearance and furnishings belonging to the cities of the period.

It is believed that the financial challenges that began in the third century worsened throughout the fourth century. Although the conversions and alterations of structures with conspicuous commercial identity, such as the Agoras and colonnaded streets, can be attributed entirely to financial reasons, the notifications in spaces such as theaters and temples cannot be explained solely on financial grounds. Aside from the financial problems, it should be noted that the difference in Christians' perceptions of the world and the city could often impede the maintenance and repair of such pagan structures.

The colonnaded streets of the Roman Period should be evaluated as urban and public spaces. Columned streets that crossed cities and connected the city's various focal points were places of dense circulation. With their extravagant architecture and monumental public and religious structures, colonnaded streets were not only axes for transportation but also a showplace. The colonnaded streets altered with time and were shifted away from their street form since they were one of the spaces that were difficult to maintain and repair in Late Antiquity. However, it is also known that, in some circumstances, they were made to be more magnificent than before, beyond the continuation of maintenance and repairs.

In Late Antiquity, agoras which were another form of public spaces were likewise subjected to numerous interventions. There were a few instances of agoras that had been fully stripped of their commercial function and converted into religious structures in a few smaller cities. While in several of the more financially powerful cities, there was either partial change or no intervention.

Theaters were the center of the Dionysus cult in Antiquity, as well as the performance venues where plays that were frowned upon by the early Christian fathers were staged. Although the theaters that were not suited for conversion in terms of their forms are sometimes observed to have been used as stone warehouses to be utilized in new constructions, it can be stated that they were typically preserved as monumental embellishments of cities. However, it is understood that places with a Christian identity were included between the two instances from Anatolia. It can be argued that the Side theater, in particular, was repurposed as a martyr cult area.

The temples were undoubtedly the most important pagan structures in the cities. The temples were known to be converted into churches or other functional structures in some cities. However, in certain cities where temples were important enough to constitute the city's symbol, only the holy place was removed, saving the city from its pagan identity. It is believed that these instances continued to exist as city symbols and urban ornaments - decorum urbanum.

Although the construction and maintenance of urban, public, and religious spaces, which are a product of cultural memory and a tool for its transposition, are the result of collective memory, their construction was supported by those with power, because their physical existence was an indicator of power and authority. The shift in power in Late Antiquity was experienced in the form of a transition from the boules and pagan rulers formed by the nobility of the city in the Roman Imperial Period to a "benevolent" urban nobility filled with more bishops and less Christian. Although it is well known that new power-holders sometimes opted to destroy the spectacular monuments of the past, it can be suggested that they preferred to alter/convert them rather than destroy them in general.

Therefore, the issue of alteration and conversion of pagan spaces in Late Antiquity is one that can be addressed with various problems and solutions utilizing various instances. As a conclusion based on the instances that we have attempted to address in this study as a summary, it can be stated that the financial dimension is the most important determining element in the continuity of cultural memory, which can come into question in the urban dimension and has a preservative approach. In fact, the lack of a preservative approach was induced by the insufficient budgets of the small assemblies of the small cities, while perhaps most of the people of Late Antiquity had an ongoing sense of belonging to the city, while they glanced at the magnificent structures of the past with admiration and longing and were proud of their city for having these structures. As a matter of fact, we can personally state that the reason why preservation and the sense of belonging to the city were stronger in larger cities such as Side, Perge, Miletos, Aphrodisias, and 
Ephesos was the financial power that these cities held in the Late Antiquity. In the partially small cities such as Elaiussa Sebaste and Phaselis, about which we have commented in the light of archaeological data, the awareness on preservation of urban spaces was not clearly observed.

Key words: Byzantine art, Late Antique Period, Pagan, Christian, Architecture, Urban transformation

Öz: Antik Dönemde kentlerin sahip oldukları yapılı çevrenin oluşmasında en önemli etken, kent meclisini oluşturan varlıklı kent soyluların maddi destekleri olmuştur. Kent soyluların yaşadıkları kenti güzel ve yaşanılır kılma isteklerinin sonucu olarak ortaya çıkan yapılaşmanın niteliği, hiç şüphesiz hem kentin hem de kendilerinin maddi gücü ile doğru orantılı olmalıdır. Geç Antik Dönemde Roma İmparatorluğu genelinde görülmeye başlayan ekonomik sıkıntılar ve buna bağlı olarak artan vergiler, varlıklı vatandaşların kentsel boyuttaki bayındırlık harcamalarının eskisine oranla daha az olmasına yol açmıştır. Geç Antik Dönem'de ekonomik ve idari güç pagan kent soylulardan Hıristiyan din adamlarına ve Hıristiyan hayırseverlere geçmiştir. Güç dengesinin değişimi kentlerde Hıristiyan dini yapıların hızla yayılmasını beraberinde getirmiştir. Yeni ihtiyaca yönelik dini yapıların kentsel yapılı çevrede kendine yer bulabilmesi her zaman çok kolay olmamıştır. Bu sorunun çözümü olarak da pagan geçmişe özgü yapıların form ve işlev değişiklikleri ortaya çıkmıştır. Bu noktada, pagan karakterli bazı yapıların yok edildikleri, bazılarının kısmen ve bazılarının da tamamen dönüştürüldükleri görülür. Bu dönüşümün boyutu ve niteliği ise yine kentin ekonomik gücüyle doğru orantılı olarak ortaya çıkmaktadır. Ekonomik olarak daha iyi durumdaki, görece daha büyük kentlerde yalnızca eski anıtsal yapıların korunması ya da kısmi dönüşümleri değil, aynı zamanda kentsel mekanların da bakım, onarım ve yenileme çalışmalarının da devam ettiği görülür. Tamamen reddedilen eski dini inançlarla özdeşleşmiş mekanların korunması, kültürel belleğin devamlılığı ve korumacı bir anlayışın varlığını gösterir. Ancak, bu korumacı yaklaşımın görece zengin kentlerde daha yoğun olarak takip edilebilmesi bu bakış açısının oluşabilmesinin ekonomik güçle de ilgili olduğu şeklinde açıklanabilir.

Anahtar Kelimeler: Bizans Sanatı, Geç Antik Dönem, Pagan, Hıristiyan, Mimari, Kentsel dönüşüm

\section{Giriş}

Bu çalışmada Geç Antik Dönem'de ${ }^{1}$ kentsel boyutta söz konusu olan “dönüşüm”ün olası tüm nedenleri dikkate alınmakla birlikte, daha çok ekonomik faktörlerin gerekçelerinin ortaya konulmasına çalışılmıştır. Bu konuda başvurulan veriler, dönemin ekonomik kayıtlarından ya da doğrudan ekonomi ile ilgili arkeolojik buluntulardan çok, yoğunluğu ve niteliği kentten kente fark eden anıtsal boyuttaki kamusal yapılar ve kentsel mekanlar olmuştur. Sinırlı sayıda örnek üzerinden yapılan bu çalışmada, daha çok Anadolu'nun batı ve güney bölgelerinde yer alan kentler ele alınmıştır. Bu seçimin nedeni, arkeolojik çalışmaların bu bölgelerde yoğunlaşmasından dolayı, görece veri fazlalı̆̆ıdır.

Klasik bir Roma kentinde kent halkı, kent ve kentin insanlara sunduğu mekanlarla etkileşim içinde, sosyal bir yaşam sürmektedir. Agora, tiyatro, sütunlu caddeler, hamamlar vb. diğer yapılar, kent halkının günlük yaşam içinde yoğun olarak bir araya geldiği, toplumsal ve kentsel mekanlar olarak işlev gören yapılardır. İç mekan kullanımının sıradan halk için yasak olduğu tapınaklar da gösterişli cephe mimarileriyle birer kentsel mekan olarak kabul edilebilir.

Yaşadıkları kentle gurur duyan Antik Dönem insanı için kentlerinin güzelliği ve ihtişamı diğer kentlerle bir rekabet konusu olmuş ve bu durum, dönem kentlerinin görünüşünü ve donanımını doğrudan etkileyen unsurlardan biri olmuştur.

Antik dönemde kent soylularının oluşturduğu bouleler kentin bayındırlık ve imar işlerini üstlenen, kente dair kararların alındığı meclisler olarak işlev görmektedir. Merkezi yönetimin kentlerdeki karar alıcı organı gibi çalışan bu meclislerin varlığı, yerleşimin kent statüsüne sahip

\footnotetext{
${ }^{1}$ Geç Antik Dönem kavramının içerdiği tarih aralığı tartışmalı olmakla birlikte, bu çalışmada 4.-6. yüzyıllar arası kabul edilmiştir.
} 
olup olmadığının temel göstergesi olarak kabul edilmektedir (Liebeschuetz, 1999, s. 2). Kent meclisinin sayısal anlamdaki büyüklügü ise kentin büyüklüğü ile genellikle doğru orantılıdır. ${ }^{2}$

Kentli olmaktan gurur duyulan ve aidiyet hissinin en üst noktada olduğu Antik Dönemde bouleyi oluşturan üyelerin, kent için harcama yapmaktan kaçınmadıkları görülür. Üçüncü yüzyılda başlayan ekonomik sıkıntılar ve artan vergiler, yerel aristokrasinin ekonomik gücünü de azaltmaya başlamış ve meclis üyeliği yavaş yavaş daha az tercih edilir bir görev olmuştur (Jones, 1966, s. 240).

Valiler kentlerde inşa faaliyetlerinin bir diğer önemli banisi olarak belirmektedir (Ceylan 2016, s. 542-543). Dördüncü yüzyıl ve 5. yüzyılın ilk yarısı boyunca yayınlanan bir dizi yasa, valilerin yeni inşa ve belediye hizmetlerinden çok kamu yapılarının bakım ve onarımına yönelmeleri gerektiğini ısrarla belirtir. Belediye hizmetlerinin devamlılığının sağlanması, vergi toplama yükümlülüğü ve buna bağlı olarak vergilerdeki eksiklerin ise bouleler tarafından karşılanması yine yasalarla belirlenmiştir. Bu nedenle, kent soyluları 4. yüzyılda orduda ya da bürokraside yüksek dereceli bir görev edinmek ya da kiliseye katılmak gibi, vergi muafiyeti sağlayan görev arayışına girmeye başlamıştır. Bu durum karşısında merkezi yönetim bir dizi yasak ve cezalarla meclis görevlerinin devamlılığını sağlamaya çalışmış ve hatta bu görevi babadan oğula geçen bir sistem haline getirmiştir. Dördüncü yüzyılın sonlarına doğru İmparator I. Theodosius (379-395) tarafından çıkarılan bir yasa ise, bir kamu yapısı inşasında gönüllü olan bani ve bağışçıları 15 yıl boyunca yapının bakım ve onarımından sorumlu tutmaktadır (Ceylan, 2016, s. 543-544). Tüm bu yasaklar, zorlamalar ve cezalar nedeniyle, 4. yüzyılda kent meclisi üyeliği neredeyse istenmeyen bir yükümlülüğe dönüşmüştür.

Merkezi yönetim tarafından kent meclislerine uygulanan bu yasak ve zorlamalar kentsel ve kamusal alanların inşası, bakımı ve onarımı konusunda devlet ve meclis bütçesinin yetersizliğini gözler önüne sermektedir. Agora, tiyatro, meydan gibi kentsel ve kamusal alanların yaşatılmasına yönelik bu merkezi zorlamalar, Geç Antik Dönem'de kentsel aidiyet duygusunun, tamamen yok olmamakla birlikte, giderek azaldığının bir göstergesidir.

Bütün bunlardan, 3. yüzyılda başlayan ekonomik sıkıntıların, 4. yüzyıl boyunca artarak devam etmiş olduğu anlaşılmaktadır. Agora gibi ticari niteliği ön planda olan mekanlarla, sütunlu caddelerin geçirdiği dönüşüm ve değişimler, öncelikle ekonomik nedenlere dayandırılabilse de, tiyatro ve tapınak alanı gibi mekanların geçirdiği değişimleri salt ekonomik gerekçelerle açıklamak mümkün değildir. Ekonomik sıkıntıların yanında, Hıristiyanların dünya ve kent algılarındaki farklılı̆̆ın, bu türden pagan karakterli yapıların bakım ve onarımlarına zaman zaman ket vurduğu düşünülmelidir.

\section{Kamusal Mekanların Geç Antik Dönemdeki Kullanımları}

Geç Antik Dönemde kentsel mekanlarda görülen değişim/dönüşümlerin en belirgin alanlarından birini agoralar oluşturur. Kilikia Bölgesi kentlerinden Elaiussa Sebaste bir ticari amfora üretim merkezi ve bu nedenle de bölgenin en önemli liman kentlerinden biridir. Yedinci yüzyılın ortasına kadar yaşamın kesintisiz olarak devam ettiği bilinen Elaiussa Sebaste'de agora olarak nitelendirilen alan, 5. yüzyılda işlevini yitirmiş ve içine vaftizhanesi ile birlikte bir kilise inşa edilmiştir (Giobbe, 2010, s. 14). Alandaki bu dönüşüm, kilise inşası uğruna klasik kent görünümünden vaz geçilmiş olduğu şeklinde yorumlanabilir. Elaiussa Sebaste'de agoranın birkaç metre doğusunda ve agoraya yapılan kilise ile yaklaşık aynı döneme tarihlendirilebilecek bir başka kilise daha yer almaktadır (Schneider, 2016, s. 479-481). Doğu-batı ekseninde art arda iki kilisenin aynı dönemde yapılmış olması agoranın dönüştürülmesinin gerekçesini anlamayı güçleştirmektedir. Elaiussa Sebaste, iki limanı ve dar bir yarımada üzerinde yer alan liman yapılarının dışında, kıyıda

\footnotetext{
2 Örneğin, Atina kent meclisi "geleneksel” olarak 500 üyeden oluşmaktayken, Suriye kentleri için 600 kişiden oluşan kent meclisleri standart gibi görünmektedir. Bununla birlikte, Antiochia meclisinin 1200 üyeden oluştuğu aktarılmaktadır (Jones, 1986, s. 724).
} 
dar bir yamaç üzerinde yer alan bir kenttir. Kentin mevcut yapılı çevresinin, artan Hıristiyan nüfusun ihtiyacı olan dini mekanların yapımı için gerekli, yeteri kadar boş alanı içermemesi muhtemeldir. Bu nedenle, kentin zaten küçük olan agorası, bir kilise için yeniden düzenlenmiş olmalıdır. Geç Antik Dönemde aktif bir liman kenti olan Elaiussa Sebaste'nin agora ya da benzeri bir ticari mekan ihtiyacı ise yarımada üzerinde düzenlenen yeni bir alanda giderilmiş olmalıdır.

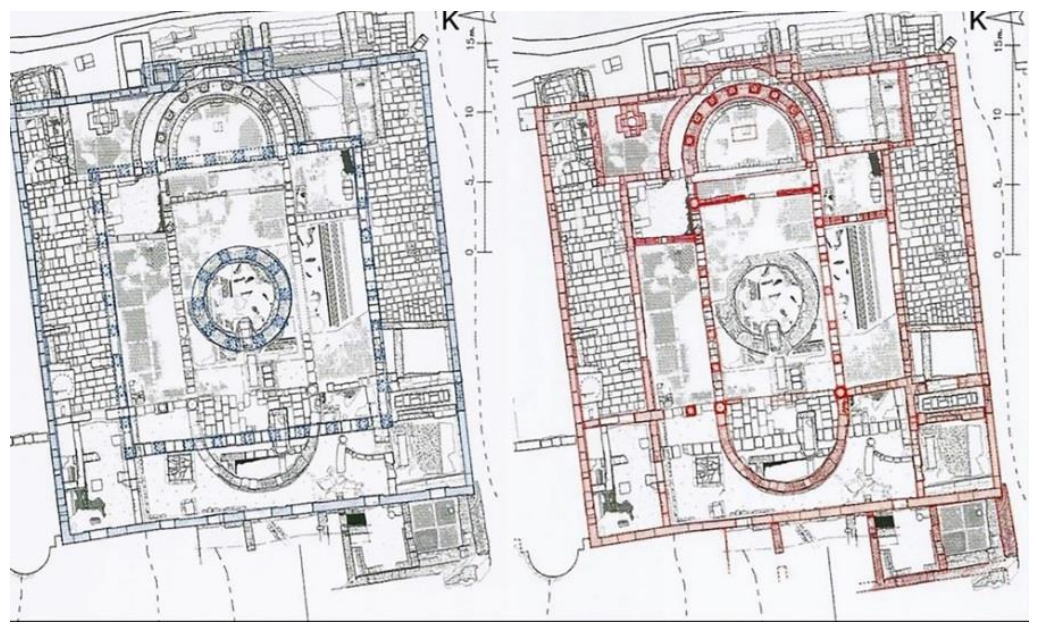

Resim 1: Elaiussa Sebaste Agora ve Kilise Evresi, Kaynak: (Schneider, 2008)

Agoranın kiliseye dönüştürülmesi konusunda benzer bir uygulama, Lykia'da küçük bir liman kenti olan Phaselis için de söz konusudur (Schäfer, 1981, Tafel:46). Üç limana sahip bir ticaret kenti olan Phaselis’te de agoranın kuzeyine ve büyük bir bölümünü kaplayacak şekilde bir kilise inşa edilmiştir. Böylelikle agora ticari işlevini tamamen yitirmiş görünmektedir. Kentin, asıl ticaret limanı olan Güney Limanı'ndan başlayarak kent merkezine ulaşan ana cadde üzerindeki agorada görülen bu dönüşüm, Hıristiyanlıkla birlikte Phaselis'in antik dönem kimliğinden, kısmen de olsa, vazgeçilmeye başlandığını göstermektedir.

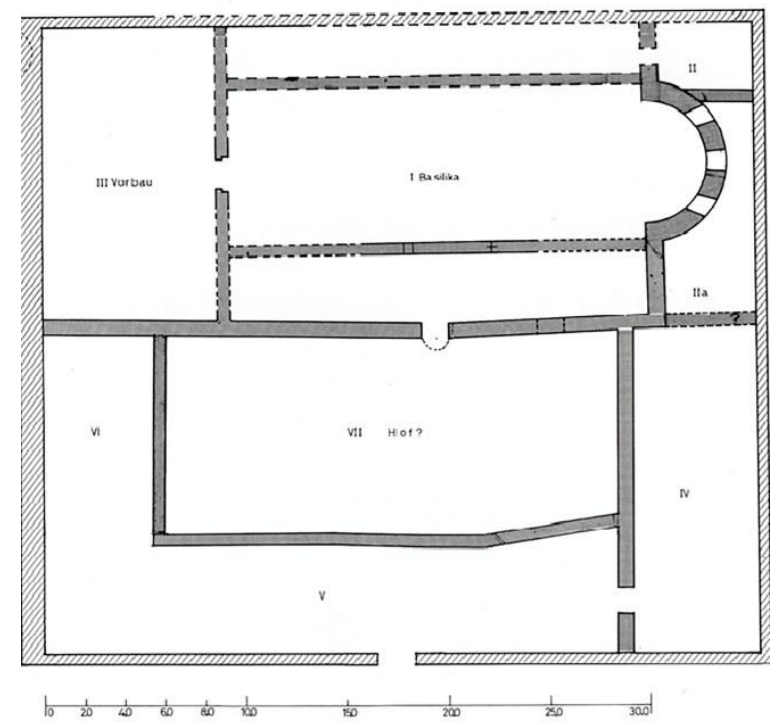

Resim 2: Phaselis Agorasına yapılan kilise. Kaynak: (Schäfer, 1981)

Agaroları tamamen iptal edilen ve dönüştürülen iki örnek sonrasında Xanthos Agorası, kısmi değişikliği ile farklı bir örnek olarak belirmektedir. Xanthos Agorasının güneybatı köşesine 6. yüzyıl içinde bir kilise, küçük bir şapel ve küçük bir yapı grubu eklenmiştir (Des Courtils, 2003, 
s. 55). Bu durum, kentte agoranın halen kullanılmaya devam ettiğini, ancak ticari işlevin yapının her noktası için geçerli olmadığını akla getirmektedir. Bu noktada, agoraların 5. yüzyıl boyunca kullanılmaya devam edildikleri, ancak eski canlılıklarını yitirmeye başladıkları görüşü dikkati çekmektedir. $\mathrm{Bu}$ dönem, tam da kent meclislerinin işlevlerini tamamen kaybetmeye başladıkları dönemdir (Ceylan, 2000, s. 40-41).

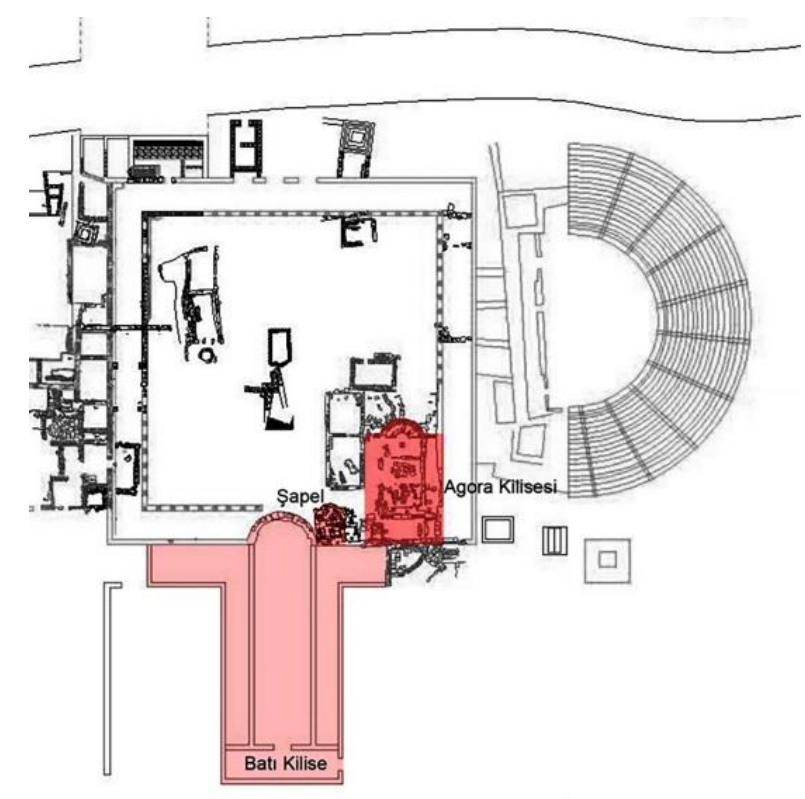

Resim 3: Xanthos Agorası ve Kilise. Kaynak: (Mısırlı - Özgüven, 2018)

Pamphylia Prima'nın metropolisi Side'nin agorası ise Geç Antik Dönemde dönüşüm geçirmeyen, bir takım mekânsal değişikliklerle birlikte asli işlevini devam ettiren bir örnek olarak görülür. M.S. 2. yüzyıla tarihlendirilen Side agorası (Mansel 1978, s. 166), bir yarımada üzerine kurulmuş olan kentin en dar yerinde, tiyatronun sahne duvarı ile bitişik olacak biçimde tiyatronun doğusuna inşa edilmiştir. Tiyatronun sahne binasının doğu duvarında yer alan kapı açıklıkları, tiyatro ile agora arasında doğrudan bağlantı sağlamaktadır. Her iki kamusal yapı arasındaki bu organik ilişki ve vaziyet planında görülen tasarım bütünlüğü, yapıların bir kompleks olarak birlikte tasarlanıp inşa edildiğini düşündürmektedir (Öztekin, 2017, s. 78).

Daha geç bir dönemde agoranın üç köşesinde yer alan dükkanların ön bölümleri iptal edilerek, yerlerine mermer kaplama ve zemini mozaikle döşenmiş eksedralar eklenmiştir. Ayrıca büyük dükkanların iç mekan düzenlemelerinde değişikliğe gidilmiş ve gerektiğinde duvarları da yükseltilmiştir (Mansel 1956, s. 3). Bu uygulama, agoranın bu dönemde halen kullanımda olduğu, bakım ve onarımının yapılmasının ötesinde, zengin ve gösterişli kılmak için çaba ve para harcanabildiğini göstermektedir. Ayrıca, agoranın güneybatısında yer alan bir kapı açıklığı, ticaret agorası ile devlet agorası olarak nitelendirilen M Binası arasında sütunlu bir yola işaret etmektedir. Bu yolun batısında, Attius Philippus Duvarı olarak literatüre geçmiş olan duvara bitişik durumda yer alan dükkanların da Geç Antik Dönem boyunca kullanımda oldukları anlaşılmaktadır (Alanyalı, 2016, s. 254-255). Side agorasına dair bu veriler, 4. yüzyıl sonrasında agoraların, siyasi işlevlerini yitirdikleri ve canlılıklarını kaybetmeye başladıkları ve asıl sirkülasyonun sütunlu caddeler üzerindeki dükkanlara kaydığ 1 yönündeki değerlendirmelere katılmakla birlikte (Ceylan, 2000, s. 40-41), Side'de agoranın halen yoğun biçimde kullanılan bir kentsel mekan olarak varlığını sürdürmeye devam ettirdiğini göstermektedir. 


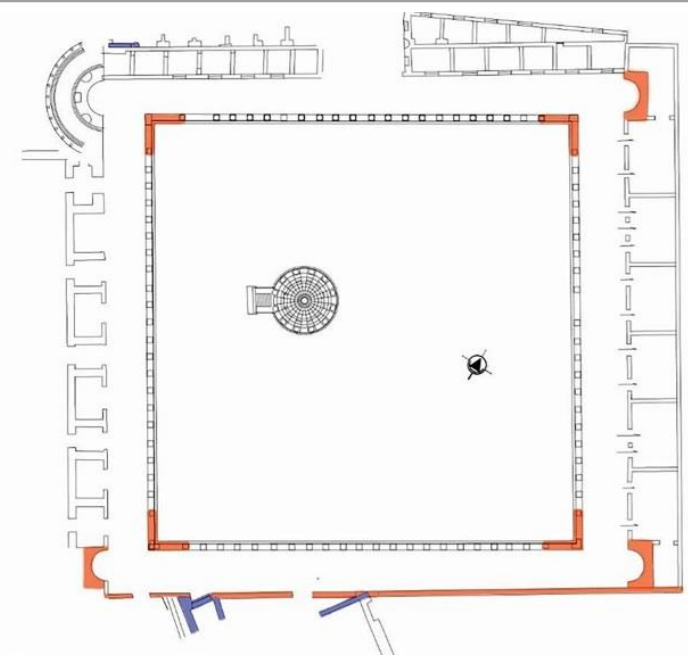

Resim 4: Side Agoras1, Kaynak: (Öztekin, 2017)

Agoraların korunarak ve donanarak kullanımının devam ettiği bir diğer örnek Laodikeia Merkez Agorasıdır. Roma İmparatorluk Dönemine tarihlendirilen agoranın zemini Erken Bizans Döneminde onarılmış ve agoranın ortasına, üzerinde bir aziz heykelinin olduğu düşünülen korinth tipte başlığa sahip bir anıt sütun dikilmiştir (Şimşek, 2013, s. 183; Şimşek, 2018, s. 95).

Geç Antik Dönemde sıklıkla sözü edilen olgulardan biri, sütunlu caddelerin sivil işgaller nedeniyle geçirdikleri değişimlere dairdir. Pek çok kent örneğinde bunu tespit etmek mümkündür, ancak bu durumu bir Geç Antik Çağ kuralı olarak görmek, artık değişmesi gereken bir bakış açısının ürünüdür. Nitekim Pamphylia Secunda'nın metropolisi Perge'nin kuzey-güney uzanımlı sütunlu caddesi, ortasinda bulunan ve kuzeydeki anitsal nymphaiondan gelen bir su kanalı ile oldukça gösterişli ve ünlüdür. Cadde Antik, Geç Antik ve Erken Ortaçağ Dönemi boyunca bu ihtişamını korumuş, ancak 9-10. yüzyıl gibi geç bir tarihte batı portikonun bir bölümü üzerine yapılan küçük bir kilise ile kısmen ve oldukça küçük bir ölçekte değişikliğe uğramıştır. ${ }^{3}$

Aynı caddenin güney bölümünde doğu portiko üzerinde görülen mozaik döşeme, sütunlu caddelerin 5. yüzyıl gibi, kentlerin antik karakterlerini kaybetmeye başladıklarının ileri sürüldüğ̈̈ bir dönemde, bakım ve onarımının sürdüğünü göstermektedir. Perge A Kilisesi’ne yakın bir konumda yer alan mozaik döşemede adı geçen Presbyter Matronianos adı, onarımda dini erkin ekonomik olarak yer aldığını ortaya koymaktadır (Işıklıkaya, 2010, s. 380).

Perge'nin komşusu Side'de ise aynı dönemde caddelerin bütüncül bir onarıma tabi tutulduğu anlaşılmaktadır. Bu süreçte, daha öncesinde sıkıştırılmış toprak zemine sahip olan sütunlu caddelerin portikolarındaki uygulamada, onarımın ötesine geçildiği ve kaldırım zeminlerinin ilk kez mozaik ile döşenmiş olduğu görülmektedir. İri boyutlu tesseralarla yapılmış olan döşeme Geç Antik Dönem özellikleri sergilemektedir (Mansel, 1978, s. 27). Tarihlendirme önerisini sütunlu caddenin agora yakınındaki bölümünde saptanan mozaik döşemedeki yazıt desteklemektedir (Mansel vd., 1956, s. 95-96; Nollé, 2001, s. 483).

Side sütunlu caddelerinde onarım ve yenileme çalışması sadece zemin uygulamalarıyla sınırlı kalmamış, sütun kaidesi, sütun ve sütun başlığı gibi taşıyıcı elemanlar da büyük oranda yenilenmiştir. Sütun başlıklarını ise Prokonnesos atölyelerinden getirilmiş, 5. yüzyıla

\footnotetext{
${ }^{3}$ Perge'nin Geç Antik Dönem ve sonrasına dair bilimsel bir çalışma henüz yapılmamıştır. Cadde üzerinde yer alan küçük kilise de henüz yayınlanmış değildir. Ancak, "basit tip" olarak tipolojiye dahil edilmesi gereken kapalı haç planlı küçük kilise, plan tipi itibariyle 9-10. yüzyıllar içinde değerlendirilebilir. Küçük kilise, üzerine yapıldığı batı stoa üzerinde sürmesi gereken sirkülasyonu engelleyecek şekilde yapılmamıştır. Büyük oranda stoanın yola yakın tarafına ve kanal üzerine inşa edilen kilisenin batısında yer alan boşluk, stoadaki hareket sürekliliğini devam ettirecek kadar geniştir.
} 
tarihlendirilen korinth tipte başlıklar oluşturmaktadır. Mozaik ve mermer malzemenin kullanıldığı, kentin caddelerine dair bütüncül bir onarım çalışmasının maliyeti, Side'nin bu dönemde sahip olduğu zenginliği ortaya koymaktadır (Yıldırım, 2017, s. 199).

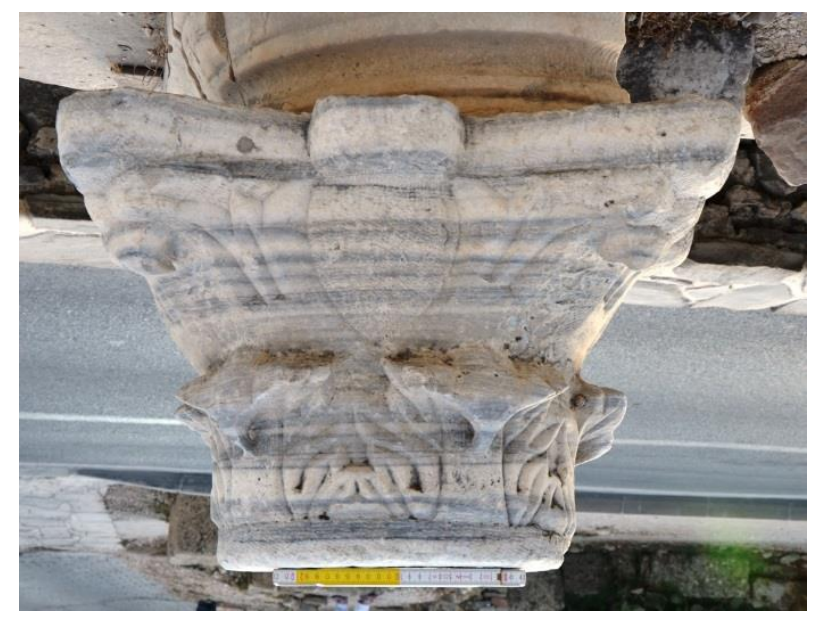

Resim 5: Side Sütunlu Cadde, Geç Antik Dönem onarımında kullanılan sütun başlığı.

Geç Antik Dönem'de Side'de sütunlu caddeler sadece onarım ve yenilemeye sahne olmamış, aynı zamanda yeni kentsel donatıların da yer aldığı sirkülasyon alanları haline gelmiştir. Ticaret agorası, tiyatro, hamam ve tak yapısının oluşturduğu kentin orta noktasında da bir su mimarisi yoğunluğu görülmektedir. Kentin liman bölgesinden sonra en yoğun sirkülasyonun olduğu agora ve tiyatro çevresinde Geç Antik Dönem'de yapılan çeşmelerle kentin ortasındaki meydan niteliğindeki alan bir cazibe merkezi haline getirilmiştir (Yıldırım, 2015, s. 523-524). ${ }^{4}$

Benzer bir durum Ephesos için de geçerlidir. Kentin sütunlu caddelerinin Geç Antik Dönem'de kapsamlı bir şekilde yapılaşmaya açılmadığı anlaşılmaktadır. Bununla birlikte, yer yer yeni düzenlemelerin yapıldığ 1 , Embolos'un araç girişini engellemek için yayalara yönelik yeniden elden geçirildiği bilinmektedir. Bu dönemdeki en dikkat çekici uygulama ise Arcadiane'nın yapılmasıdır. İmparator Arcadius Dönemi'nde (395-408), limandan tiyatroya uzanan Liman Caddesi kapsamlı bir onarıma tabi tutulmuştur. Onbir metre genişliğinde ve $500 \mathrm{~m}$. uzunluğundaki cadde üzerine, üzerinde dört havarinin heykellerinin yer aldığı düşünülen dört anıtsal sütun dikilmiş ve bu anıt grubu caddenin görkemini arttırmıştır (Foss, 1979, s. 57-58).

Arcadiane dışında, Geç Antik Dönem'den itibaren Ephesos çok sayıda onarım ve yenileme geçirmiştir. İçerisinde Celsus Kütüphanesi'nin de olduğu işlev değişikliği geçiren yapılar, yeni cadde ve sokak düzenlemeleri, kısmen eski anıtsal pagan yapılardan devşirilen malzemelerle inşa edilmiş yeni cadde çeşmeleri ve benzeri pek çok mimari uygulama ile kentin refah ve ekonomik gücünün sergilenmesi amaçlanmıştır. ${ }^{5}$

Tiyatrolar, Antik Dönem kentleri için vazgeçilmez bir toplumsal ve kentsel mekan olarak bilinmektedir. Tiyatrolar sadece oyunların sahnelendiği "eğlence" mekanları değil, aynı zamanda Dionysos kültünün kentlerdeki merkezi ve bu nedenle de aslında kentlerin en büyük tapınakları olarak algılanabilir (Alanyalı, 2011, s. 78). Bu özellik, onların temelde pagan karakterli yapılar olarak kabul edilmesini gerektirir. Bu nedenden dolayıdır ki, başta İoannes Chrysostomos olmak

\footnotetext{
${ }^{4} \mathrm{Bu}$ alandaki çeşmelerden birinin (Üç Havuzlu Çeşme) 3. yüzyılda yapıldı̆̆ı belirtilmektedir (Grewe 1994, s. 203). Vespasian Anıtı olarak anılan yapının da Bizans Dönemi'nde çeşmeye dönüştürüldüğü Eyice tarafından ileri sürülmektedir (Eyice 1975, s. 435). Böyle bir dönüşüm, kentin genel tarihçesi dikkate alındığında yine Geç Antik Dönem içerisinde gerçekleşmiş olmalıdır.

${ }^{5}$ Ephesos'a bu çalışmada -çalışmanın boyutları ve Ephesos’un büyüklüğü nedeniyle- çok kısa şekilde değinilmiştir. Kentin Geç Antik Dönemdeki imar hareketliliği ve kente yapılan Geç Antik Dönem müdahaleleri ile ilgili daha detaylı ve kapsamlı bir çalışma için bkz. Pülz, 2011, s. 47-75.
}

Turkish Studies, 16(7) 
üzere, pek çok din adamı tarafından Hıristiyanların tiyatrolara gitmesi hoş görülmemiştir (Saradi, 2006, s. 310-314). ${ }^{6}$

Tiyatrolar formları ve boyutları nedeniyle yapısal dönüşüme uygun olmayan yapılardır. Bu nedenle, işlevlerini yitirdikten sonra çoğunlukla atıl durumda kalmış ve ilerleyen süreçte pek çok kentte yeni yapılaşmalar için taş deposu niteliğine bürünmüştür. $\mathrm{Bu}$ noktada, 6. yüzyılda İustinianus'un tarih yazıcısı Prokopius'un agora, hipodrom, tiyatro gibi yapıları kentlerin süsü olarak nitelendirmesini ve bu yapılardan övgüyle söz etmesini vurgulamak gerekir (Saradi, 1995, s. 41. Procopius III. iv. i8-v. 4, (s.201). Prokopius'un bakış açısı Geç Antik dünyasında kent elitleri için de geçerli olmalı ki, pek çok tiyatro oldukça iyi durumda en azından bu dönemi geçirebilmiştir. Nitekim, 6. yüzyıl boyunca ve 7. yüzyılın sonuna kadar büyük kentlerde tiyatroların asli işlevlerini sürdürdükleri tartış1lmaktadır (Mango, 1981, s. 337-353; Whittow 1990, s. 18).

Tiyatrolar için Geç Antik Dönem'de bilinçli ve kapsamlı bir yıkım ve tahribatın söz konusu olmadığını söyleyebilsek de, bakım, onarım ve koruma konusunda aynı duyarlılığın gösterilmediğini de belirtmek gerekir. Tiyatrolar, olasılıkla ekonomik nedenlerden dolayı, kendi haline bırakılmış gibidir. Ancak, Anadolu'dan birkaç örnek, tiyatroların Geç Antik Dönem'deki dönüşüm ve onarımları ile ilgili ilginç veriler sunmaktadır. Aphrodisias Tiyatrosu 7. yüzyıla kadar kullanılmaya devam edilmiş ve henüz oyunlar için kullanılırken, skenefronsun içi Hıristiyanlık konulu freskolarla bezenmiştir (Saradi, 2006, s. 315-316.). Mekanda liturjik herhangi bir elemanın olmaması tiyatro içinde şapel vb. bir mekandan ziyade, dua amaçlı bir mekan oluşturulduğunu düşündürmektedir (Cormack, 1991, s. 114-115). Laodikeia Batı Tiyatrosunun 6. yüzyılda bir onarım geçirmesi ve Kuzey Tiyatrosunun bazı oturma basamaklarına İustinianus Dönemi'ne (527565)S tarihlendirilen haçların ve kristogramların kazınmış olması, Erken Bizans Dönemi'nde her iki tiyatronun da aktif ve Hiristiyanlar tarafindan da kullanılmakta olduğunu göstermektedir (Şimşek, 2013, s. 226, 237-240).

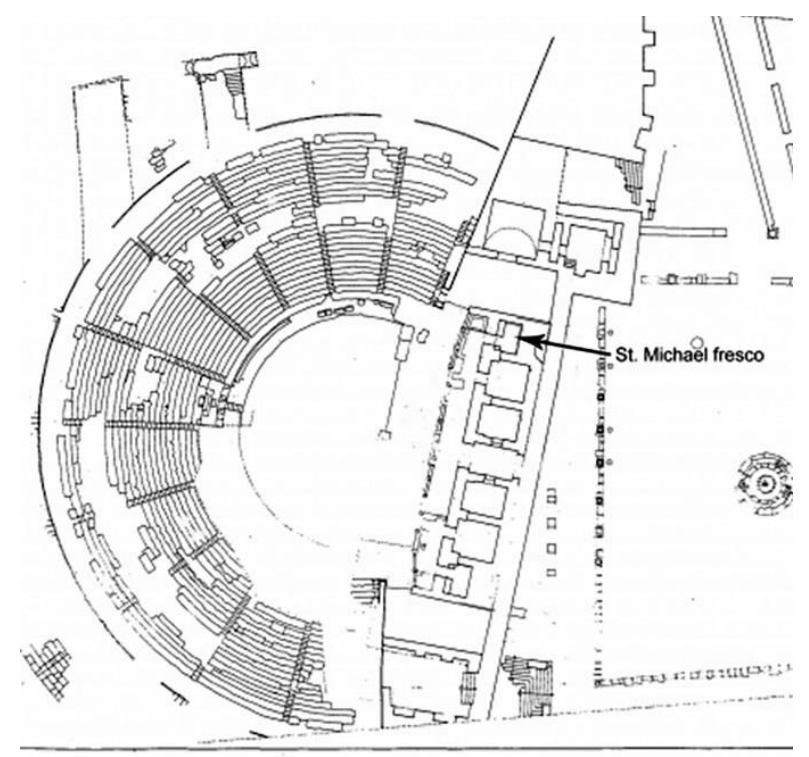

Resim 6: Aphrodisias Tiyatrosu, Kaynak: (Bowes, 2014)

Side tiyatrosunun Hıristiyanlar tarafından Geç Antik Dönem'deki kullanımı daha belirgindir. Caveanın kuzey bölümünde yer alan iki yazıt, orada oturacak kişilerini kim olduklarını göstermektedir. "Prepositus'un Yeri" olarak okunan ilk yazıtta geçen prepositus titri, Geç Antik Çağda askeri nitelikli bir unvan olmasının yanı sıra, kilise görevlilerinin rütbelerini belirtmek

${ }^{6}$ Ayrica bkz. Schaff, 2019, s. 175.

www.turkishstudies.net/turkishstudies 
amacıyla da kullanılmıştır. Yazıtın yanında yer alan haç betimlemesi nedeniyle, bu yazıtın ruhban sınıfına mensup, kilise ile ilgili bir memura ait olduğu neredeyse kesindir (Yıldırım, 2013, s. 139140).

Bununla birlikte, Side Tiyatrosu'nda yapısal bir takım ekler ve değişikliklerin de varlığı söz konusudur. Sahne binasının güney ucunda Erken Bizans Dönemi’ne tarihlenebilecek İncil konulu freskoların olduğu bir mekan vardır. Orkestranın kuzeyine de, duvarında İsa'nın seçilebildiği tonozlu, küçük bir mezar odası eklenmiştir. Kuzey paradosta da arkosoliumlu bir dizi mezar yer almaktadır. Yapısal eklerin, tiyatro işlevini yitirdikten sonra mı yapıldıkları kesin olmasa da pagan nitelikli bir yapının kutsanarak Hıristiyanlaştııılmış olduğu düşünülebilir. Tiyatroda gerçekleştirilen eklemelerin İmparator Diokletianus Dönemi'nde (284-305), dokuz Hıristiyanın Side Tiyatrosu'nda vahşi hayvanların önüne atılarak cezalandırıldığı ve literatüre "dokuz martyrler" adıyla geçmiş olan olayın anısına yapılmış olabileceği akla gelmektedir. ${ }^{7}$ Tiyatronun kuzey paradosuna bitişik galerinin ise bir kiliseye dönüştürülmesi, yapının pagan geçmişiyle bağını sadece form düzeyine indirmiş ve tiyatroyu tamamen Hıristiyan karakterli anıtsal bir yapıya dönüştürmüştür (Y1ldırım, 2013, s. 143-144).

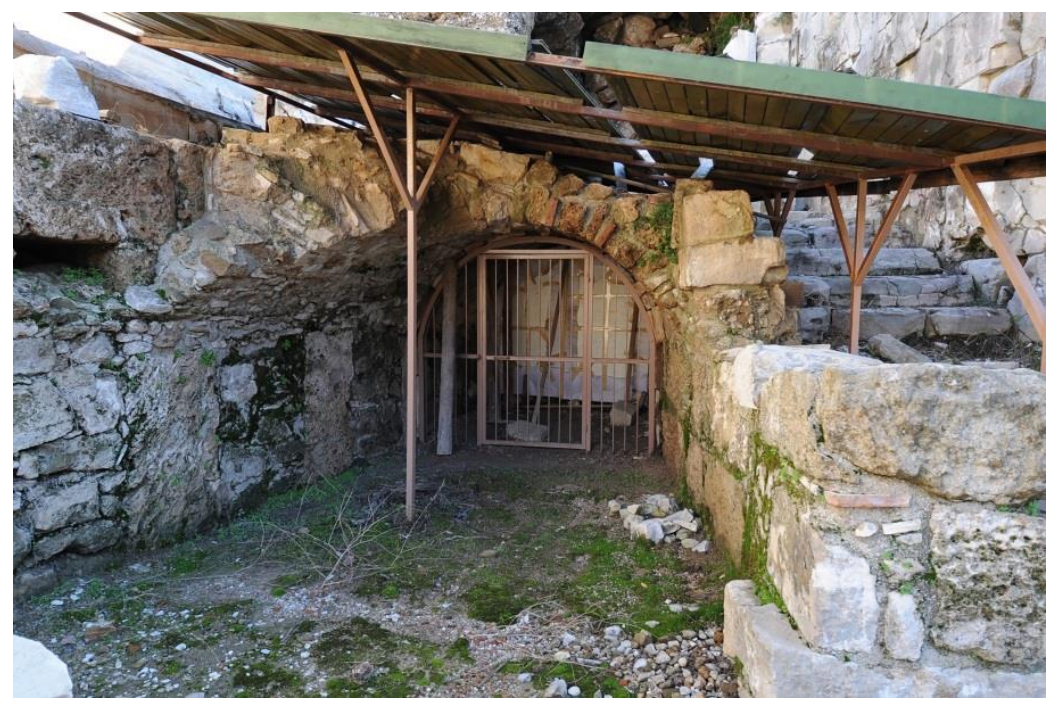

Resim 7: Side Tiyatrosu sahne binasının güneyindeki freskolu mekan, Kaynak: (Yıldırım, 2013)

\footnotetext{
${ }^{7}$ Tarragona, Salona ve Caesarea Maritima'daki amfitiyatro ve stadion gibi gösteri mekanlarında benzer uygulamalar söz konusudur. Geç Antik Dönem'de bu yapılardaki ekleme ve müdahalelerin martyr kültüyle ilişkili olduğu tartışılmaktadır. Bkz. Bowes, 2014, s. 95-97.
} 


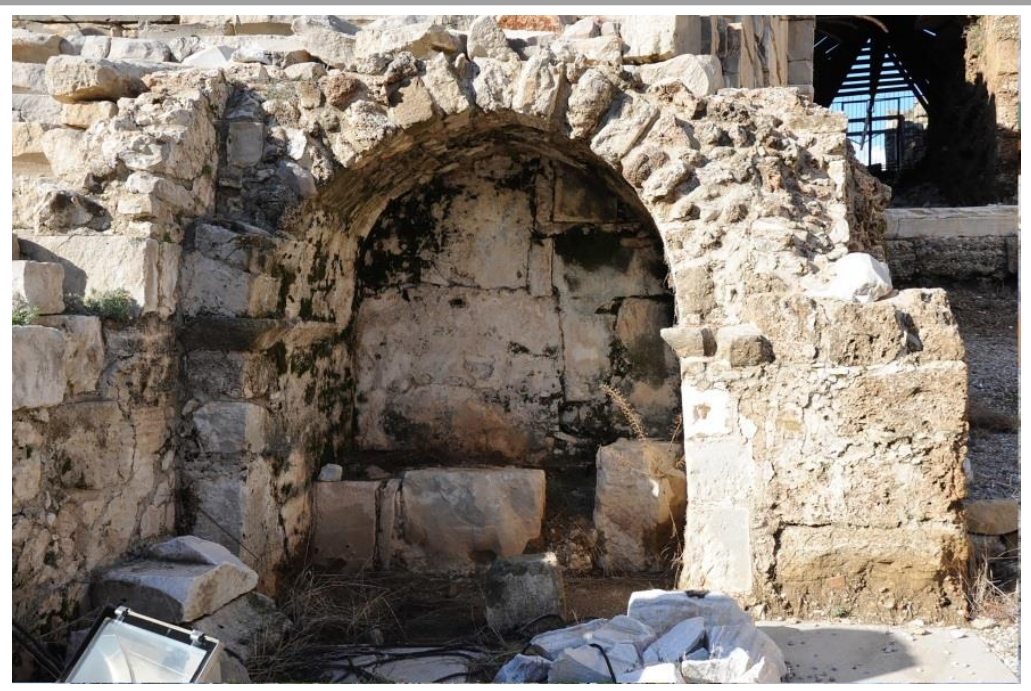

Resim 8: Side Tiyatrosu orkestranın kuzeyindeki mezar odas1, Kaynak: (Yıldırım, 2013)

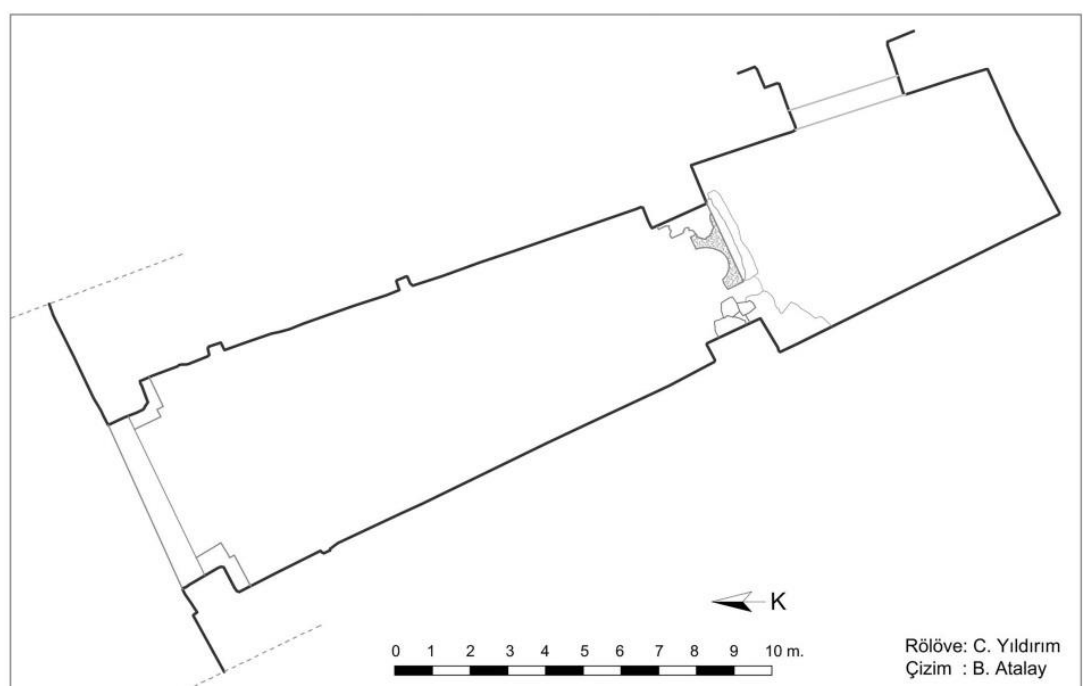

Resim 9: Side Tiyatrosu kiliseye dönüştürülen galeri, Kaynak: (Yıldırım, 2013)

Tiyatronun Side halkı için olası dönüştürülmüş mekânsal anlamının yanında, anıt olarak da önemli olduğu anlaşılmaktadır. Geç Antik Dönem'de yaşanan bir depremde tiyatronun dıș galerisini oluşturan ve üst caveasını taşıyan fil ayakları yıkılmış ve yapı cephesi bir harabe görünümüne bürünmüştür. Agorayı limana bağlayan kentin ana caddesi üzerindeki yapının, caddeden görünen cephesi tamamen onarılmıştır. $\mathrm{Bu}$ onarımı belgeleyen dört farklı yazıtta "proconsül ve pater civitatis (şehrin babası)" ünvanlarına sahip iki ayrı isimden söz edilmektedir (Yıldırım, 2013, s. 141). Beşinci ve altıncı yüzyıllara tarihlendirilen bu onarım sürecinin, Side'nin sivil yetkilileri eliyle gerçekleştirildiği anlaşılmaktadır. Bu yüzyıllar, kentlerde sözün ve yetkinin artık piskoposların eline geçtiği bir dönemdir. Görünüşe göre, Hıristiyanlığın tek tanrı inancı, pagan karakterli yapılara karşı alınan tavırda asıl belirleyici neden olmuştur ve her ne kadar Side Tiyatrosu pagan geçmişinden uzaklaştırılmaya çalış1lsa ve içerisine Hıristiyan nitelikli eklemeler yapılsa da, yine de dini önderlik tarafından onarımının üstlenilmediği düşünülebilir. Ancak, burada belirtmek gerekir ki, onarım sadece agora ve liman arasındaki yoğun sirkülasyonun olduğu cadde cephesinde yapılmıştır. Tiyatronun kentsel sirkülasyondan uzak batı ve güney tarafındaki yıkıntı ise olduğu gibi bırakılmıştır. Belli ki, 5-6 yüzyıllarda anıtsal bir yapının bütüncül onarımı, Side kenti 
için bile fazla pahalıydı ve yalnızca insanların sıklıkla kullandıkları alanlara bakan bölümler onarılmış ve kentin imajı kurtarılmaya çalışılmıştır.

Geç Antik Dönem'de kentlerin pagan geçmişleriyle en sıkı bağını, hiç şüphesiz tapınaklar oluşturmaktadır. $\mathrm{Bu}$ nedenle, gerek halkın ve gerekse kilisenin tapınak alanlarına bakışı, bu dönemin en önemli olgularından biridir. İmparatorluk geneline yayılan ama aslında sanıldığından daha az yoğunluktaki yıkıma varan tepki, elbette önem arz etmekte ve literatürde yerini bulmaktadır. Daha çok Orta Doğu ve Kuzey Afrika eyaletlerinde karşılaşılan ve yerel bir uygulama olarak dikkat çeken planlı ve bilinçli tapınak yıkımları arasında, I. Theodosius'un onayı ile gerçekleştirilen İskenderiye'deki Serapis Tapınağı ve kütüphane yıkımı dikkati çekmektedir (Saradi Mendelovici 1990, s. 49). Ancak, tapınaklara karşı genelde söz konusu olan tutum ise terk etmek ve ilgilenmemek şeklinde olmuştur. Tapınaklara asıl zarar veren olgu ise, terk edilmişlik sonrasında bakımsız geçirdikleri zamanın etkisidir (Spieser 2001, s. 10-13). Farklı bir örnek olarak Atina'daki tapınaklar, İskenderiye'deki yıkımdan yaklaşık bir yüzyıl sonra lanetlenmiş, buna karşın yıkılmamış ve en nihayetinde 7. yüzyılda kiliseye dönüştürme işlemleri başlamıştır. Atina' daki bu görece geç tarihli uygulama, kentin güçlü pagan geçmişine bağlanmaktadır (Mango, 2007, s. 70).

Tapınakların kapatılması, ziyaretinin yasaklanması ve kült objelerinin kaldırılması yönünde yasalar çıkarılmış olsa da, yıkılmalarını yasaklayan, hatta korunmasını emreden yasalar da çıkarılmıştır (Cod.Theo., 16.10.18). Tapınakların kullanımının yasaklanmasının ardında, Hıristiyanlık merkezli bir bakış açısı varken, bu yapılara "decorum urbanum” yani kent süsü, antik geçmişin görkemli anıtları ve kentli olma gururunun kaynağ1 olarak bakılması (Ceylan, 2016, s. 549), kente dair aidiyet hissinin halen güçlü olduğu bir döneme işaret etmektedir.

407-408 tarihli bir yasa, kapatılan tapınak yapılarını kiliselere devretmektedir (Cod.Theo., 16.10.20). Bu tarihten sonra, tapınak alanlarının tasarrufu tamamen kentlerdeki dini yöneticilere, yani piskoposlara geçmiş olmalıdır. Tapınak alanlarının 5. yüzyıldan itibaren Anadolu'daki dönüşümünde birbirinden farklı uygulamaların varlığı söz konusudur. Genellikle tapınak yapısının çeşitli mimari müdahalelerle kiliseye dönüştürüldüğg̈ görülmektedir. Diocaseria Zeus-Olbios (Wannagat ve Westphalen 2007), Aphrodisias Aphrodite (Cormack 1990), Didyma Apollon (Wiegand 1952) ve Elaiussa Sebaste Augustus (Kaplan 2009, s. 28) tapınakları bu grup içinde sayılabilir. ${ }^{8}$ Side AA Bazilikası ve Olympos Piskoposluk Sarayı ve kilisesi gibi örneklerde ise, kilisenin tapınak temenosu içine inşa edildiği görülür (Öztaşkın 2017, s. 63).

Aphrodisias'ta erken tarihli kiliselerin kent dışına yapıldıkları görülmektedir. Aphrodite Tapınağı üzerine yapılan kentin en büyük kilisesi ise ancak 6. yüzyılda inşa edilmiştir. Tapınağın girişindeki tetrapylon 400 yılı civarında onarıldığında ise yalnızca tanrıçanın kabartmaları silinmiş ve Erken Bizans Dönemi boyunca kullanımda kalmıştır. Adını tanrıça Aphrodite'den alan kentin ismi ise ancak 7. yüzyılda Stauropolis olarak değiştirilmiştir (Niewöhner 2019, s. 202).

Beşinci yüzyılın başına tarihlendirilen Side AA Bazilikası, Apollon ve Athenaya adanmış olan ve kentin liman bölgesinde yan yana inşa edilmiş iki tapınağın doğusuna ve temenosu içine yapılmıştır. Kilisenin inşası sırasında kuzeydeki Apollon Tapınağı'nın tamamı atrium içinde kalırken, güneydeki Athena Tapınağı'nın güney yarısı atrium dışında bırakılmıştır. Bu düzensizlik başka bir tartışma konusu olmakla birlikte, tapınakların yalnızca cellalarının yıkıldıkları ve cellayı çevreleyen sütun dizilerinin korundukları anlaşılmaktadır. Kilise atriumunda tapınakların belli oranda korunması kent halkının, yapıların estetik değerleri ile bir kent süsü, "decorum urbanum" olarak, varlıklarının devamlılığı yönündeki tavırlarından kaynaklanmaktadır. Benzer şekilde Gerasa, Baalbek ve Hauran'da tapınakların yalnızca cella ve adytonları yıkılmıştır. Böylece, yapılar dini iç mekanlarından ve dolayısıyla işlevlerinden arındırılmış ve dış mekanlarıyla kenti güzelleștiren unsurlar olarak varlıklarını sürdürmüşlerdir (Yıldırım, 2013, s. 180-181).

\footnotetext{
${ }^{8}$ Anadolu'dan diğer bazı örnekler için bkz. Ceylan (2000); Bayliss (2004).
} 


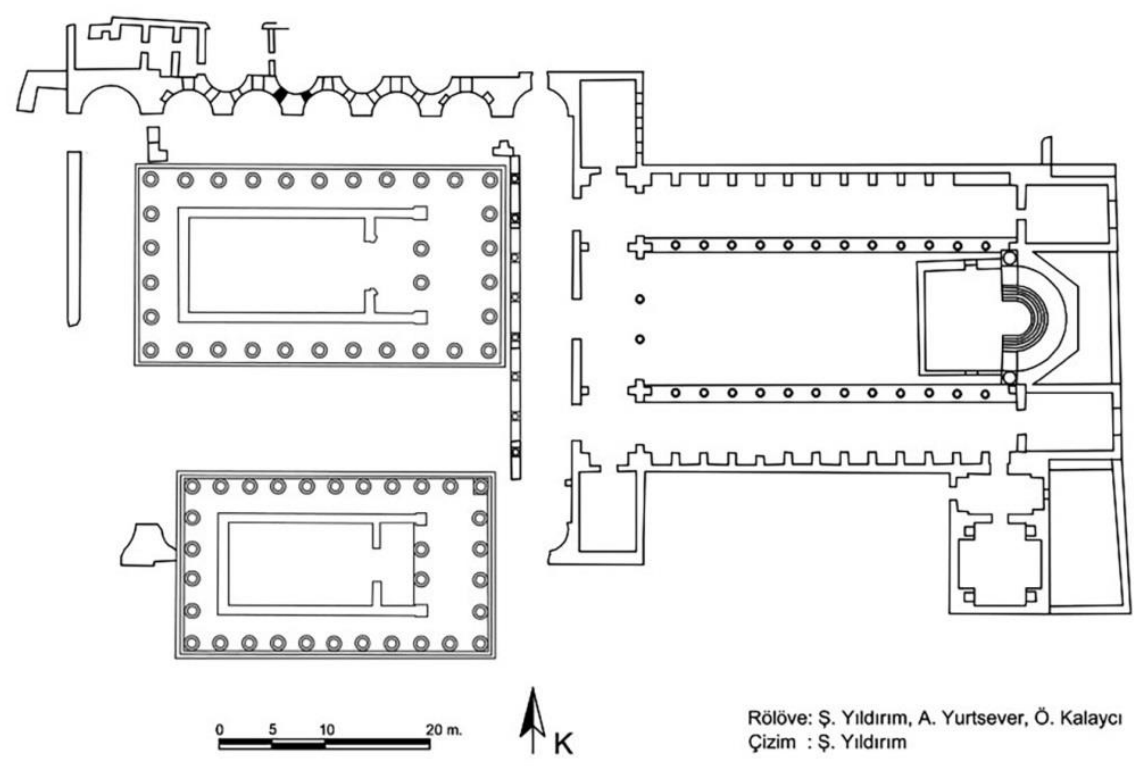

Resim 10: Side AA Bazilikası ve atriumundaki Apollon ve Athena Tapınakları, Kaynak: (Yıldırım, 2013)

Side'de tapınakların yasal olarak kapatılmaları ve yapıların atıl kalmalarından sonra, tapınak alanına AA Kilisesi'nin yapılması, paganizme karşı kazanılmış bir zafer olarak "ideolojik"; tapınak arazisinin kiliseye devredilmesi ile "ekonomik"; kentin hafızasında yer etmiş olan dini bir merkezin devamlılı̆g ş̧eklinde "sosyolojik" ve yerli yabancı pek çok insanın sürekli bir sirkülasyon içinde olduğu bir alanda yer almasından dolayı, tapınaklar gibi kente ait bir simge olarak "sembolik" gerekçelerden birinin, birkaçının ya da tümünün kabulüyle açıklanabilir (Yıldırım, 2013, s. 255). Yapımının gerekçesi ve şekli ne olursa olsun kesin olan durum, AA Kilisesi'nin, kente dair bir belleğin değişerek de olsa, mekânsal boyutuyla devam ettiğidir.

\section{Sonuç}

Kültürel belleğin bir sonucu ve aktarımı için de bir aracı olan kentsel, kamusal ve dini mekanların kurgulanması ve yaşatılması her ne kadar ortak belleğin bir sonucu olsa da, fiziki olarak varlıkları bir güç ve iktidar göstergesi olmasından dolayı, yapımları güce sahip olanlar tarafından desteklenir. Geç Antik Çağ'da gücün el değiştirmesi, Roma İmparatorluk Dönemi'nde kentin soyluları tarafindan oluşturulan bouleler ve pagan yöneticilerden, daha çok piskoposlara ve daha az olmak üzere, Hıristiyan ve "hayırsever" kent soylularına geçmesi şeklinde olmuştur. Yeni güç sahiplerinin geçmişin görkemli anıtlarını zaman zaman yok etme yolunu seçtikleri bilinse de, daha genel olarak bunun yerine değiştirme/dönüştürme yolunu seçtikleri düşünülebilir.

Sonuç olarak, pagan mekanların Geç Antik Dönem'de gösterdiği değişim ve dönüşüm konusu, sayısız örnek üzerinden farklı problem ve farklı çözümlerle tartışılabilecek bir konudur. Burada bir özet olarak ele almaya çalıştığımız örnekler üzerinden bir sonuç önerisi ise, kentsel boyutta söz konusu olabilecek ve korumacı bir yaklaşıma sahip kültürel bellek sürekliliğinde, ekonomik boyutun asıl belirleyici unsur olduğudur. Aslında, Geç Antik Dönem insanının belki de büyük bir kısmında, hala kente dair aidiyet hissi ve geçmişin görkemli yapılarına beğeni ve özlemle bakabilme ve bu yapılara sahip oldukları için kentleriyle gurur duyma durumu hakimken, ${ }^{9}$ korumacı bir yaklaşım tarzının eksikliğinin nedeni, küçük kentlerin küçük meclislerinin sahip oldukları yetersiz finansal güçle açıklanabilir. Nitekim, arkeolojik veriler ışığında görüş ileri

\footnotetext{
${ }^{9}$ Miletos antik kent dokusunun Erken Bizans Dönemi boyunca korunduğu ve bu korumanın gerekçesi olarak da kente dair aidiyet hissi ve Miletoslu olmanın gururu ile açıklanabileceği ileri sürülmektedir (Niewöhner, 2019, s. 201).
} 
sürebildiğimiz Elaiussa Sebaste, Phaselis gibi görece küçük kentlerde, kentsel mekanlara dair korumacılık bilinci net bir şekilde izlenemezken; Side, Perge, Miletos, Aphrodisias ve Ephesos gibi daha büyük kentlerde korumacılık ve kente dair aidiyet duygusunun daha güçlü olması, bu kentlerin Geç Antik Dönem'de sahip oldukları ekonomik güçle ilgili olmalıdır.

\section{Kaynakça}

Alanyalı, H.S. (2011). Side'nin Roma dönemi panteonu. Anadolu/Anatolia, 37, 75-92.

Alanyalı, H.S. (2016). Side 2014 yılı kazı ve araştırmaları. 37. Kazı Sonuçları Toplantısı, C.1, 253276.

Bayliss, R. (2004). Provincial Cilicia and the archaeology of temple conversion, BAR International Series 1281.

Bowes, K. (2014). Christians in the amphitheater? The «Christianization » of spectacle buildings and martyrial memory, MEFRM, 126/1, 93-114. https://doi.org/10.4000/mefrm.1807

Ceylan, B. (2000). Batı Anadolu bölgesinde bulunan antik dönem anıtsal yapılarından dönüşı̈rrülmüş bazilika planlı kiliseler, [Yayımlanmamış doktora tezi].Hacettepe Üniversitesi Sosyal Bilimler Enstitüsü.

Ceylan, B. (2016). Geç antik dönem kentlerinde gerileme/devamlılık modellerine kanunlar üzerinden bir bakış. OLBA XXIV, 535-554.

Cormack, R. (1990). The temple as the cathedral. J. Roueche-K. Erim (Ed.), Aphrodisias Papers I., 75-88, Journal of Roman Archaeology Supp. Series No. 2.

Cormack, R. (1991). The wall-painting of St. Michael in the theatre, R. R. R. Smith - K.T. Erim (Ed.), Aphrodisias Papers 2, 109-122, Journal of Roman Archaeology Supp. Series No. 2.

Des Courtils, J. (2003). Ksanthos ve Letoon rehberi. Ege Yayınlar1.

Eyice, S. (1975) İstanbul arkeoloji müzesinde Bizans-Türk çeşmesi. Belleten, XXXIX, 429-446.

Foss, C. (1979). Ephesus after antiquity: A late antique, Byzantine and Turkish city. Cambridge University Press.

Giobbe, C. (2010). La periodizzazione, E.E. Schneider, (Ed.), Elaiussa Sebaste III, L'Agora Romana, 11-22. Ege Yayınları.

Grewe, K. (1994) Die römische wasserleitung nach Side (Türkei). Antike Welt 25, 192-203.

Iş1klıkaya, R. I. (2010), Perge mozaikleri, macellum, güney hamam ve geç dönem meydanı doğu portiği, [Yayımlanmamış doktora tezi]. İstanbul Üniversitesi Sosyal Bilimler Enstitüsü.

Jones, A.H.M. (1966), The decline of the ancient World. Longman.

Jones, A.H.M. (1986). The later Roman empire, 284-602: A social, economic and administrative survey. Volume II. The Johns Hopkins University Press.

Kaplan, D. (2009) Ein neuer kultvorschlag für den tempel in Elaiussa Sebaste (Kilikien). OLBA, XVII, 23-32.

Liebeschuetz, J. H. W. G. (1999). Antik kentin sonu, J. Rich (Ed.) Geç Antik Çağda Kent 1-47, (S. Güven - E. Güven, Çev.). Homer Kitapevi.

Mango, C. (1981), Daily life in Byzantium. Jahrbuch der Österreichischen Byzantinistik, 30, 337353.

Mango, C. (2007). Yeni Roma imparatorluğu. (G.Ç. Güven, Çev). Yapı Kredi Yayınları. 
Mansel, A.M. (1956) Side agorası ve civarındaki binalar. Türk Tarih Kurumu Basımevi.

Mansel, A.M. (1978). Side, 1947-1966 yılları kazıları ve araştırmalarının sonuçları. Türk Tarih Kurumu.

Mansel, A. M., Bean, G., İnan, J. (1956). Side agorası ve civarındaki binalar 1948 yll kazılarına dair rapor. Türk Tarih Kurumu Yayınları.

Mısırlı, A., Özgüven, B. (2018). Bizans Dönemi’nde Kentin Dönüşümü: Agoraların Yeniden Kullanımına İlişkin Bir Değerlendirme, Kubat, A. S. (Ed.) "DeğişKKent”, Değişen Kent, Mekan ve Biçim, Türkiye Kentsel Morfoloji Ă̆ II. Kentsel Morfoloji Sempozyumu, 539552. Marmara Kültür Yayınları.

Niewöhner, P. (2019) Byzantine preservation of ancient monuments at Miletus in Caria christian antiquarianism in western Asia Minor, J. Borsch-O. Gengler-M. Meier (Ed.), Die Weltchronik des Johannes Malalas im Kontext spätantiker Memorialkultur, 191-216. Franz Steiner Verlag.

Nollé, J. (2001). Side im altertum. Geschichte und zeugnisse I. Geographie, Geschichte,Testimonia, griechische und lateinische Inschriften (1-4). Habelt.

Öztaşkın, G.K. (2017). Olympos kenti episkopeion yapı topluluğu, B.Y. Olcay Uçkan (Ed.) Olympos I 2000-2014 Araştırma Sonuçları, 49-78. AKMED.

Öztekin, V. (2017). Side agora-tiyatro kompleksi, [Yayımlanmamış yüksek lisans tezi]. Anadolu Üniversitesi Sosyal Bilimler Enstitüsü.

Pharr, C. (1952) The Theodosian code and novels and the sirmondian constitutions, translation with commentary. Glossary And Bibliography.

Pülz, A. (2011) Bizans döneminde Ephesos'un görünümü, F. Daim-S. Ladstätter (Ed.), Bizans Dönemi'nde Ephesos, (ss.47-75). Ege Yayınları.

Procopius. Buildings, E. H. Warmington (Ed.), 1971. Harward University Press.

Saradi-Mendelovici, H. (1990). Christian attitudes toward pagan monuments in late antiquity and their legacy in later Byzantine centuries. Dumbarton Oaks Paper 44, 47-61.

Saradi, H.G. (1995). The kallos of the Byzantine city: The development of a rhetorical topos and historical reality. Gesta, Vol. 34, (No.1), 37-56.

Saradi, H. (2006). The Byzantine City in the Sixth Century, Literary Images and Historical Reality. Society of Messenian Archaeological Studies.

Schäfer, J. (1981). Phaselis, beiträge zur topographie und geschichte der stadt und ihrer häfen. Deutsches Archäologisches Institut.

Schaff, P. (2019). Latin Christianity: Its Founder, Tertullian: Cross-linked to the Bible (AnteNicene Fathers Book 3).MI: Christian Classics Ethereal Library.

Schneider, E.E. (2008). Doğu ile batı arasında bir liman kenti, Elaiussa Sebaste. Homer Kitabevi.

Schneider, E. E. (2016). Elaiussa Sebaste: 2014 excavation and conservation Works. 37. Kazl Sonuçları Toplantısı, C.3, 479-492.

Spieser, J. M. (2001). The christianisation of pagan sanctuaries in Greece. Urban and Religious Space in Late Antiquity and Early Byzantium, VI, 1-13.

Şimşek, C. (2013). Laodikeia (Laodicea Ad Lycum). Ege Yayınları. 
Şimşek, C. (2018). “Geç antik çağda Laodikeia”, C. Şimşek-T. Kaçar (Ed) Geç Antik Çă̆’'da Lykos Vadisi ve Çevresi, 81-116. Ege Yayınları.

Wannagat, D., Westphalen, S. (2007). The sanctuary of Zeus-Olbios and the city of Diokaisareia, H. Elton-E.Equini-Schneider-D. Wannagat (Ed.), Temple to Church, 1-24. Ege Yayınları.

Whittow, M. (1990), Ruling the late Roman and early Byzantine city: A continuous history, Past and Present, No. 129, 3-29

Wiegand, T. (1952). Didyma. Die Baubeschreibung ib Drei Banden III, Text Band.

Yıldırım, Ş. (2013). Side'nin Bizans dönemi dini mimarisi, [Yayımlanmamış doktora tezi]. Anadolu Üniversitesi Sosyal Bilimler Enstitüsü.

Yıldırım, Ş. (2015). Side müzesi’nden bir geç antik çağ çeşmesi”. OLBA, XXIII, 515-534.

Yıldırım, Ş. (2017). "Mimari plastik veriler 1şı̆̆ında erken Bizans döneminde Side'de sütunlu caddelerin onarımı", Seleucia, Sayı VII, 187-206. 